\title{
Asparagus Emergence in Fusarium-treated and Sterile Media following Exposure of Seeds or Radicles to One or More Cinnamic Acids
}

\author{
Lincoln C. Peirce ${ }^{1}$ and Heather G. Miller ${ }^{2}$ \\ University of New Hampshire, Durham, NH 03824 \\ Additional index words. asparagus decline, allelopathy, autotoxicity, Asparagus officinalis, Fusarium oxysporum
}

\begin{abstract}
Several cinnamic acids have been identified as principal toxic components of asparagus (Asparagus officinalis L.) root autotoxin and have been shown to synergize Fusarium infection of asparagus. The basis for this synergism was studied by exposing asparagus seeds and radicles from pregerminated seeds to ferulic (FA), caffeic (CA), or methylenedioxycinnamic (MDA) acids alone and in combinations of two or three of these acids. After treatment, seeds were placed in pots of peat-lite mix, and, depending on the experiment, all or half were inoculated with $F$. oxysporum (Schlecht) f. sp. asparagi (Cohen). Seedling emergence from each pot was used as a measure of toxicity. All cinnamic acids at $1 \%$ suppressed emergence compared with the control. Solutions combining FA and CA $(0.5 \% / 0.5 \%, v / v)$ were substantially more toxic than $1 \%$ solutions of either alone. Exposure of radicles (early postgermination) for 10 minutes to combined FA/CA before planting decreased emergence from pots, whereas emergence following a 10-minute exposure to $1 \%$ CA or FA alone did not differ from the controls. The 2-hour exposure to FA or to FA/CA and the 24-hour exposure to CA, FA, or FA/CA decreased emergence, with toxicity progressing as follows: CA < FA < FA/CA. Root tip squashes showed fewer mitotic figures in treated than in untreated radicles, and scanning electron microscopic (SEM) examination of the radicle epidermis revealed damage to the surface of epidermal cells and precocious root hair development, the extent of which paralleled treatment toxicity.
\end{abstract}

The decline of established asparagus beds has been related to infection of crowns and roots by fusarium diseases predominantly caused by Fusarium oxysporum and/or $F$. moniliforme (Sheld.) emend Snyd. \& Hans. (Cohen and Heald, 1941; Grogan and Kimball, 1959; Johnston et al., 1979). Although other Fusarium spp. have been isolated from infected crowns (Fantino and Fantuz, 1990; Sadowski and Knaflewski, 1990), there is no firm evidence of their role in decline.

In the 1980s, autotoxic properties of decaying asparagus roots were described, and a relationship of autotoxicity to decline, exclusive of disease, was suggested (Hartung et al. 1989; Shafer and Garrison, 1980a, 1980b, 1986; Yang, 1982; Young, 1984, 1986). Hartung and Stephens (1983, 1984), Peirce and Colby (1987) and Hartung et al. (1989) observed an interaction, as measured by seed germination and early growth, between the autotoxin and fusarium disease. Fusarium virulence increased in the presence of crude autotoxin or extracts of it, and Hartung et al. (1989) speculated that the autotoxin might predispose asparagus to increased infection by Fusarium spp. through a direct biochemical or physiological effect.

Recently, Hartung et al. (1990) and Miller et al. (1991) implicated several cinnamic acids-caffeic (CA), ferulic (FA), and/ or methylenedioxycinnamic (MDA)-in asparagus autotoxicity or allelopathy, and Rice (1984) noted previously that CA and FA inhibited germination in other crops or had been isolated from soil beneath allelopathic species. Miller et al. (1991) reported only $\mathrm{CA}$ in samples from decaying fresh asparagus roots. The numbers of seedlings emerging in pots treated with commercial CA and with CA purified from methanol extracts from asparagus roots were similar, both with and without Fusarium present. Hartung et al. (1990) found FA to be the major con-

Received for publication 12 Mar. 1992. Accepted for publication 15 July 1992. Scientific contribution no. 1765 from the New Hampshire Agricultural Experiment Station. The cost of publishing this paper was defrayed in part by the payment of page charges. Under postal regulations, this paper therefore must be hereby marked advertisement solely to indicate this fact.

${ }^{1}$ Professor of Plant Biology.

${ }^{2}$ Graduate student. stituent in aqueous extracts of dried root samples and MDA the predominant toxin in lyophilized fresh root samples. However, they found that neither alone was sufficiently toxic to account for phytotoxicity of asparagus autotoxin. The reasons for different extraction results are not clear. Exudate from decaying roots might change in composition under differing environments or stresses, or differing laboratory recovery techniques might account for more than one compound being identified as predominant toxins. Regardless, the evidence is convincing that each of these cinnamic acids is phytotoxic. We were interested in determining the extent to which each showed synergism with $F$. oxysporum and, if possible, a mechanism by which the fungus was synergized. In vivo tests therefore were designed to evaluate toxicity of commercial preparations of CA, FA, and MDA alone and in combination, with and without $F$. oxysporum present, and to examine radicles from the most toxic treatments for evidence of damage that might predispose seedlings to infection by Fusarium.

\section{Materials and Methods}

Cinnamic acid combinations (Expt. 1). Seeds of the asparagus cultivar UC-72 were soaked in a $20 \%$ solution of sodium hypochlorite for $1 \mathrm{~h}$, rinsed, and air-dried. About 450 of these seeds were placed in each of twenty-three 125-ml ehrlenmeyer flasks, and each received sufficient liquid of one of the treatments (listed in Table 1) to cover the seeds. Each acid treatment was a $1 \%$ aqueous solution (v/v) adjusted to $\mathrm{pH} 5$ to 6 with 0.1 $\mathbf{N ~ N a O H}$ to match the extraction $\mathrm{pH}$ of natural autotoxin. The percent acid was chosen based on previous studies (unpublished) showing a toxic threshold between $0.6 \%$ and $1.0 \%$ for CA. Flasks were sealed until the control showed some radicle emergence (12 days). Seeds in each flask were drained; half of the seeds in each flask were rinsed with distilled water, half were not.

Pots $(250 \mathrm{ml})$ were filled to the lower rim with peat-lite mix

\footnotetext{
Abbreviations: CA, caffeic acid; DW, distilled water; FA, ferulic acid; MDA,
} methylenedioxycinnamic acid; SEM, scanning electron microscopy. 
Table 1. Mean emergence of asparagus seeds soaked before planting in three cinnamic acids alone and in combinations and inoculated or not inoculated with Fusarium oxysporum (FO)

\begin{tabular}{llccc}
\hline \hline & & \multicolumn{3}{c}{ Emergence (no./pot) } \\
\cline { 3 - 5 } Treatment & Percent in watery & $\begin{array}{c}\text { FO- } \\
\text { inoculated inoculated }\end{array}$ & Mean \\
\hline \hline FA/MDA & $0.5 / 0.5$ & 0.3 & 1.0 & $0.6 \mathrm{a}$ \\
FA/CA & $0.67 / 0.33$ & 0.0 & 2.1 & $0.9 \mathrm{a}$ \\
FA/MDA & $0.67 / 0.33$ & 0.5 & 2.3 & $1.4 \mathrm{ab}$ \\
MDA/CA & $0.67 / 0.33$ & 1.8 & 2.1 & $1.9 \mathrm{ab}$ \\
FA/CA & $0.5 / 0.5$ & 0.3 & 3.9 & $2.1 \mathrm{abc}$ \\
FA & 1.0 & 0.4 & 3.8 & $2.1 \mathrm{abc}$ \\
FA/CA/MDA & $0.33 / 0.33 / 0.33$ & 1.6 & 3.4 & $2.5 \mathrm{a}-\mathrm{d}$ \\
CA/FA & $0.67 / 0.33$ & 0.8 & 4.5 & $2.6 \mathrm{a}-\mathrm{d}$ \\
MDA & 0.67 & 4.0 & 2.5 & $3.3 \mathrm{a}-\mathrm{e}$ \\
MDA/FA & $0.67 / 0.33$ & 3.3 & 4.6 & $3.9 \mathrm{~b}-\mathrm{f}$ \\
CA/MDA & $0.67 / 0.33$ & 2.5 & 5.6 & $4.1 \mathrm{~b}-\mathrm{f}$ \\
CA & 1.0 & 4.1 & 5.6 & $4.9 \mathrm{~d}-\mathrm{g}$ \\
FA & 0.67 & 3.9 & 6.6 & $5.3 \mathrm{~d}-\mathrm{g}$ \\
FA & 0.5 & 2.3 & 8.3 & $5.3 \mathrm{~d}-\mathrm{g}$ \\
CA/MDA & $0.5 / 0.5$ & 3.6 & 7.9 & $5.8 \mathrm{e}-\mathrm{h}$ \\
MDA & 0.5 & 5.4 & 6.8 & $6.1 \mathrm{e}-\mathrm{i}$ \\
MDA & 1.0 & 6.3 & 6.9 & $6.6 \mathrm{f}-\mathrm{j}$ \\
CA & 0.5 & 7.5 & 7.1 & $7.3 \mathrm{~g}-\mathrm{j}$ \\
H2O (DW) & --- & 7.1 & 8.1 & $7.6 \mathrm{~g}-\mathrm{j}$ \\
MDA & 0.33 & 6.0 & 9.4 & $7.7 \mathrm{~g}-\mathrm{i}$ \\
CA & 0.67 & 7.6 & 9.0 & $8.3 \mathrm{hij}$ \\
FA & 0.33 & 6.3 & 11.3 & $8.8 \mathrm{ij}$ \\
CA & 0.33 & 6.8 & 11.1 & $8.9 \mathrm{j}$ \\
\hline
\end{tabular}

${ }^{\mathrm{z}}$ Data transformed to arcsin for analysis and mean separation. Mean separation by Duncan's multiple range test, $P=0.05$.

${ }^{\mathrm{y}}$ All CA mixes equalled $1 \%$ solution in water.

(Redi-Earth; W.R. Grace, Cambridge, Mass.) amended with controlled-release fertilizer (Osmocote 3.2N-6.1P-11.6K, at 7 g.liter ${ }^{-1}$ medium). For each of the 23 treatments, 25 seeds from rinsed and unrinsed lots were placed in each of eight pots. Additional medium then was added and firmed. To each pot, 10 $\mathrm{ml}$ of either distilled water (DW) or $F$. oxysporum (FO) spore suspension (600 spores/ml) was added, and pots were sealed in separate Zip-Lock polyethylene bags. The seeded pots were placed in a shaded greenhouse (normal range 18-22C) in a split-split plot design in four replications, with DW vs. FO treatments comprising the main plots. The subplots compared rinsed and nonrinsed seeds, within which the 23 treatments (sub-subplots) were randomized. Counts were made of seedling emergence from each pot over 2 weeks. These emergence data were transformed to arcsin and processed by analysis of variance and GLM procedures of SAS (SAS Inst., Cary, N.C.). Orthogonal comparisons were made among treatments, and trend and regression analyses were used to evaluate dosage response of a given constituent.

Pregerminated seeds in cinnamic acid solutions, followed by exposure to $F$. oxysporum (Expt. 2). Disinfected asparagus seeds were pregerminated on moistened filter paper in 12 petri dishes of 150 seeds each. After 8 days, at least $50 \%$ of the seeds in each dish showed measurable radicle growth $(2$ to $5 \mathrm{~mm})$. All seed lots then were transferred to petri dishes containing one of the following four treatments: distilled water (control); CA (1\% aqueous solution, v/v); FA (1\% aqueous solution, v/v); FA/CA $(0.5 \% / 0.5 \%$ aqueous solution, v/v/v). MDA was not included in this experiment, since response to this treatment did not differ appreciably from the response to CA. Each of the CA treatments was adjusted to pH 5 to 6 as before. The amount of treatment liquid was sufficient to ensure contact with the seed and radicle surfaces. After $10 \mathrm{~min}$, seeds from four petri dishes, one from each treatment, were rinsed in distilled water and transferred to six 250-ml pots filled with moistened peat-lite mix, 20 seeds per pot. Similarly, seeds from four petri dishes were rinsed and seeded after treatment periods of 2 or $24 \mathrm{~h}$. After seeding, each pot was inoculated with FO, placed in a Zip-Lock bag, sealed, and randomized. The design was a split plot with six replications. Exposure times were the main plots, treatments were subplots. Emergence counts were made when the controls showed no further emergence; data were analyzed by the GLM procedure (SAS).

Extra germinated seeds from each treatment and exposure time were removed from treatment dishes, and the radicles were excised and placed in Farmer's fixative for $8 \mathrm{~h}$, stored in $70 \%$ ethanol at $4 \mathrm{C}$, and squashed with pressure under a cover slip in a drop of acetoorcein stain. These preparations were evaluated microscopically for mitotic irregularities. An additional 10 seeds per treatment were pregerminated in petri dishes on sterile filter paper moistened with DW and removed when radicals were 2 to $5 \mathrm{~mm}$ long. The seeds were then transferred to $1 \% \mathrm{CA}, 1 \%$ FA, $0.5 \% \mathrm{FA} / 0.5 \% \mathrm{CA}$ (all pH adjusted), and DW treatments for 10-min, 2-h, and 24-h periods. After each treatment, seeds were rinsed two to three times in DW and placed immediately in a fixative (50\% ethyl alcohol, $5 \%$ glacial acetic acid, $10 \%$ formaldehyde, by volume, in DW). The seeds were removed and washed three times in $70 \%$ ethanol for 3 to $6 \mathrm{~h}$ each time. Seeds then were taken through a tertiary butyl alcohol (TBA) dehydration series, $6 \mathrm{~h}$ in each grade, followed by three rinses of $100 \%$ TBA, 6 h/rinse. Samples were critical-point dried, mounted, and gold-coated for scanning electron microscopy (SEM).

Table 2. Significant orthogonal comparisons of groups of CA treatments.

\begin{tabular}{|c|c|c|c|}
\hline Comparison & \multicolumn{3}{|c|}{ Significance } \\
\hline Single acid comparisons & & & \\
\hline FA vs. CA + MDA & $* *$ & Ns & $*$ \\
\hline CA vs. MDA & $\underset{*}{N} \mathrm{~N}_{*}$ & NSS & $* *$ \\
\hline
\end{tabular}

${ }^{\mathrm{z}} \mathrm{FO}=10 \mathrm{ml}$ Fusarium oxysporum f. sp. asparagi spore suspension $(600$ spores $/ \mathrm{ml})$.

NS,**** Not significant or significant at $P=0.05$ or 0.01 . 
Table 3. Mean emergence of asparagus seeds soaked in three cinnamic acids, singly or in several proportions of two each.

\begin{tabular}{|c|c|c|c|c|c|c|c|c|c|}
\hline \multirow{2}{*}{$\begin{array}{c}\text { Cinnamic } \\
\text { acid }\end{array}$} & \multirow{2}{*}{$\begin{array}{c}\text { Percent in } \\
\text { solution }\end{array}$} & \multicolumn{8}{|c|}{ Emergence (no./pot) when combined with: } \\
\hline & & Water & FA & $\mathrm{CA}$ & MDA & Water & FA & $\mathrm{CA}$ & MDA \\
\hline \multirow{4}{*}{ FA } & & \multicolumn{4}{|c|}{ FO-inoculated $\mathrm{z}$} & \multicolumn{4}{|c|}{ Noninoculated } \\
\hline & 1.0 & 0.4 & --- & --- & --- & 3.8 & --- & -- & --- \\
\hline & 0.67 & 3.9 & --- & 0.0 & 0.5 & 6.6 & -- & 2.1 & 2.3 \\
\hline & 0.50 & 2.3 & -- & 0.3 & 0.3 & 8.3 & --- & 3.9 & 1.0 \\
\hline \multirow{3}{*}{$\mathrm{CA}$} & 0.33 & 6.3 & --- & 0.8 & 3.3 & 11.3 & --- & 4.5 & 4.6 \\
\hline & 1.0 & 4.1 & -- & -- & $\cdots$ & 5.6 & -- & $\cdots$ & -- \\
\hline & 0.67 & 7.6 & 0.8 & --- & 2.5 & 5.6 & 4.5 & -.. & 5.6 \\
\hline \multirow{5}{*}{ MDA } & 0.50 & 7.5 & 0.3 & --- & 3.6 & 7.1 & 3.9 & -.- & 7.9 \\
\hline & 0.33 & 6.8 & 0.0 & -- & 1.8 & 11.1 & 2.1 & -- & 2.1 \\
\hline & 1.0 & 6.3 & --- & -- & --- & 6.9 & $\cdots$ & --- & -- \\
\hline & 0.67 & 4.0 & 3.3 & 1.8 & -- & 2.5 & 4.6 & 2.1 & --- \\
\hline & 0.50 & 5.4 & 0.3 & 3.6 & -- & 6.8 & 1.0 & 7.9 & --- \\
\hline \multirow{2}{*}{ Dose mean } & 0.33 & 6.0 & 0.5 & 2.5 & -- & 9.4 & 2.3 & 5.6 & --- \\
\hline & 1.0 & 3.6 & $\cdots$ & --- & -- & 5.4 & --- & --- & --- \\
\hline \multirow{6}{*}{$\begin{array}{l}\text { Total mean } \\
\text { Significance }\end{array}$} & 0.67 & 5.2 & 2.1 & 0.9 & 1.5 & 4.9 & 4.6 & 2.1 & 4.0 \\
\hline & 0.50 & 5.1 & 0.3 & 2.0 & 2.0 & 7.4 & 2.5 & 5.9 & 4.5 \\
\hline & 0.33 & 6.4 & 0.3 & 1.7 & 2.6 & 10.6 & 2.2 & 5.1 & 3.4 \\
\hline & --- & 5.1 & 0.8 & 1.5 & 2.0 & 7.6 & 3.1 & 4.4 & 3.9 \\
\hline & & $*$ & NS & NS & NS & $* *$ & NS & & NS \\
\hline & & NS & $* *$ & NS & NS & $* *$ & $*$ & $* *$ & NS \\
\hline
\end{tabular}

${ }^{\mathrm{z}} \mathrm{FO}=10 \mathrm{ml}$ Fusarium oxysporum f. sp. asparagi spore suspension (600 spores $\left./ \mathrm{ml}\right)$.

NS,**** Not significant or significant at $P=0.05$ or 0.01 , respectively. Based on average effects in a data column. $\mathrm{L}, \mathrm{Q}=$ linear, quadratic.

Table 4. Orthogonal comparisons of emergence data following exposures of radicles for various durations to FA or CA or their combination.

\begin{tabular}{lc}
\hline \hline Comparison & Significance \\
\hline 10 min soak vs. longer soak & $* *$ \\
2 -h vs. 24-h soak & $* *$ \\
Control vs. cinnamic acid soaks & $* *$ \\
FA/CA mix vs. either FA or CA & $* *$ \\
FA vs. CA & $*$ \\
\hline
\end{tabular}

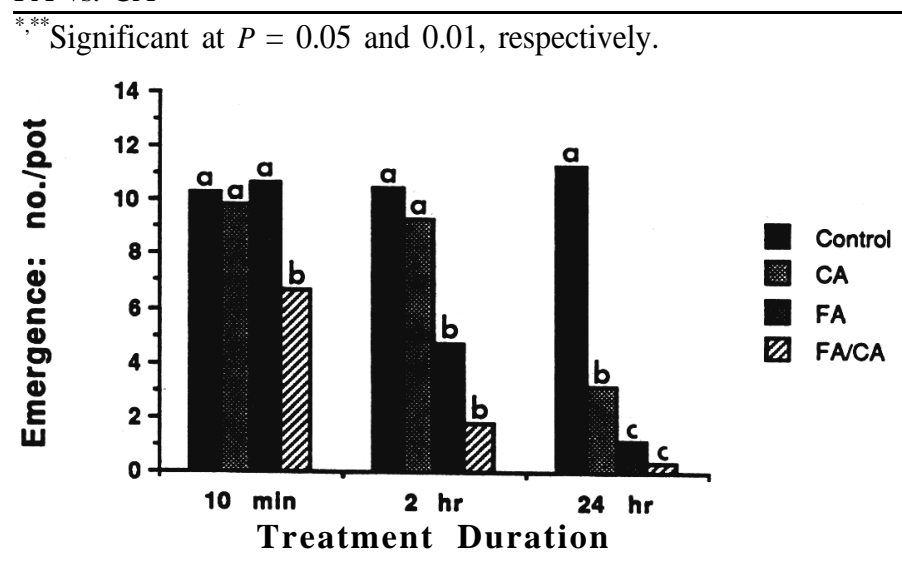

Fig. 1. Effect of cinnamic acids applied to radicles on subsequent emergence in Fusarium-inoculated medium. FA $=1 \%$ ferulic acid; $\mathrm{CA}=1 \%$ caffeic acid $\mathrm{FA} / \mathrm{CA}=0.5 \% / 0.5 \%$ mixture. Alphabetic letters within time reflect mean separation by Duncan's multiple range test, $P=0.05$.

\section{Results}

Experiment 1. In general, emergence was poor, even in controls (Table 1). In preliminary tests of cinnamic acid treatments (data not reported), the soak time needed to produce radicles was less than the 12 days required in this trial, suggesting a difference in seed quality. A follow-up study on effect of soak-
Table 5. Number of mitotic cells in root tips of asparagus radicles and appearance of radicles following treatment with FA or CA or a mixture of both.

\begin{tabular}{|c|c|c|c|}
\hline Treatment' & $\begin{array}{c}\text { Treatment } \\
\text { duration } \\
(\mathrm{h})\end{array}$ & $\begin{array}{c}\text { Mitotic cells }{ }^{\mathrm{z}} \\
\text { (no.) }\end{array}$ & $\begin{array}{c}\text { Radicle } \\
\text { appearance }^{\mathrm{y}}\end{array}$ \\
\hline \multirow[t]{2}{*}{$\overline{\mathrm{DW}}$} & 0.17 & $\begin{array}{l}5.1 \pm 1.0 \\
5.0+0.4\end{array}$ & $\begin{array}{l}\text { White } \\
\text { White }\end{array}$ \\
\hline & 2 & $5.3 \pm 0.9$ & White \\
\hline \multirow[t]{3}{*}{ CA $1 \%$} & 0.17 & $1.3 \pm 0.3$ & White \\
\hline & 2 & $0.9 \pm 0.3$ & Brown tip \\
\hline & 24 & $0.7 \pm 0.2$ & $\begin{array}{l}\text { Extensive } \\
\text { browning }\end{array}$ \\
\hline \multirow[t]{3}{*}{ FA $1 \%$} & 0.17 & $0.9 \pm 0.3$ & Brown tip \\
\hline & & $5.0 \pm 0.5$ & Brown tip \\
\hline & 2 & $0.5 \pm 0.2$ & $\begin{array}{l}\text { Extensive } \\
\text { browning }\end{array}$ \\
\hline \multirow{3}{*}{$\begin{array}{l}\mathrm{FA} / \mathrm{CA} \\
(0.5 \% / 0.5 \%)\end{array}$} & 0.17 & $1.0 \pm 0.3$ & Slight brown \\
\hline & 2 & $1.3 \pm 0.3$ & $\begin{array}{l}\text { tip and base } \\
\text { Slight brown }\end{array}$ \\
\hline & 24 & $0.4 \pm 0.2$ & $\begin{array}{l}\text { tip and base } \\
\text { Extensive } \\
\text { browning }\end{array}$ \\
\hline
\end{tabular}

${ }^{\mathrm{z}}$ Each mean based on 10 root tips, +/- SE.

${ }^{\mathrm{y}}$ Examined with stereo microscope.

ing (DW) on emergence showed maximum emergence after 4 days, even though no radicles had appeared by that time. Emergence declined thereafter, perhaps indicating oxygen deficiency in long soak treatments. High temperature in the greenhouse may have affected emergence after the pots were seeded. Although the bagged pots were shaded from direct sun, there were several episodes of unusually high daytime temperature $\left(>38^{\circ} \mathrm{C}\right)$. However, emergence in all replicates was similar and sufficient to expose treatment differences. Further, the trends observed were consistent with those of preliminary tests.

Treatment differences were more distinct in FO- than in DW- 


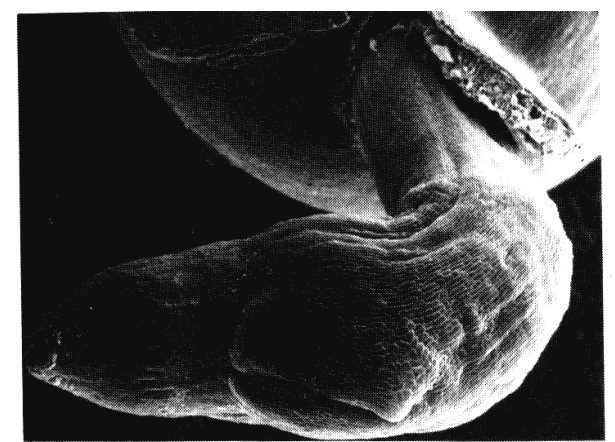

A
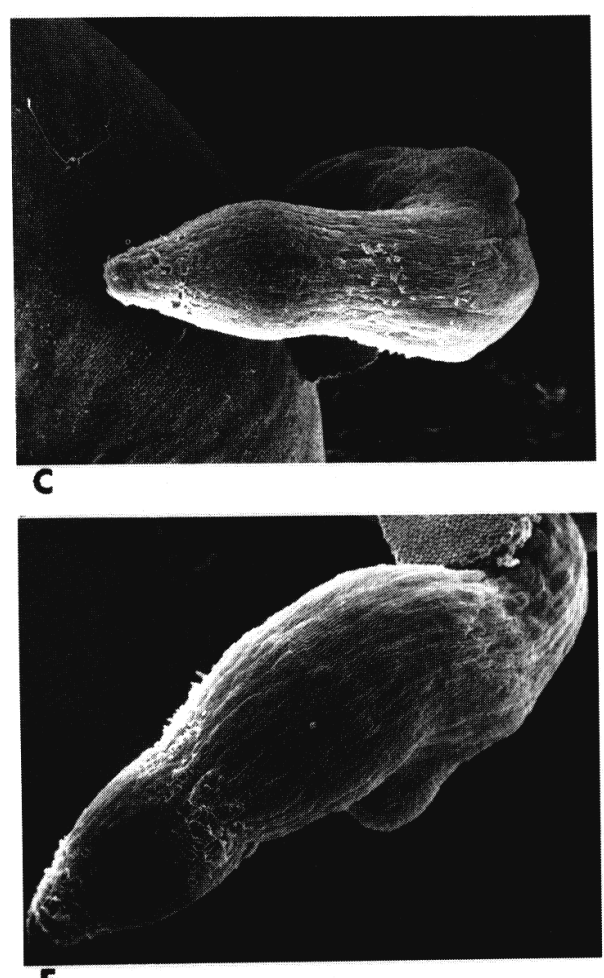

E

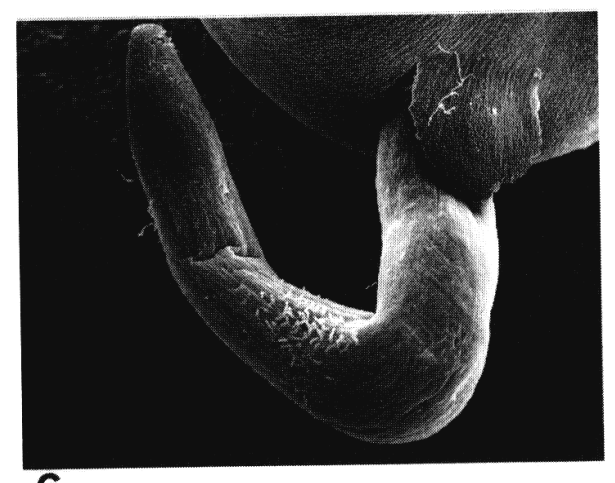

G

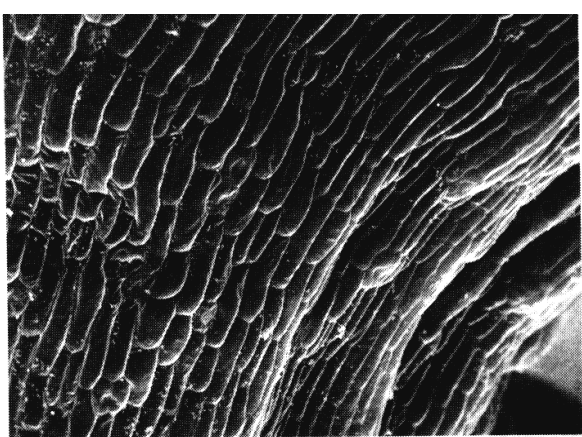

B
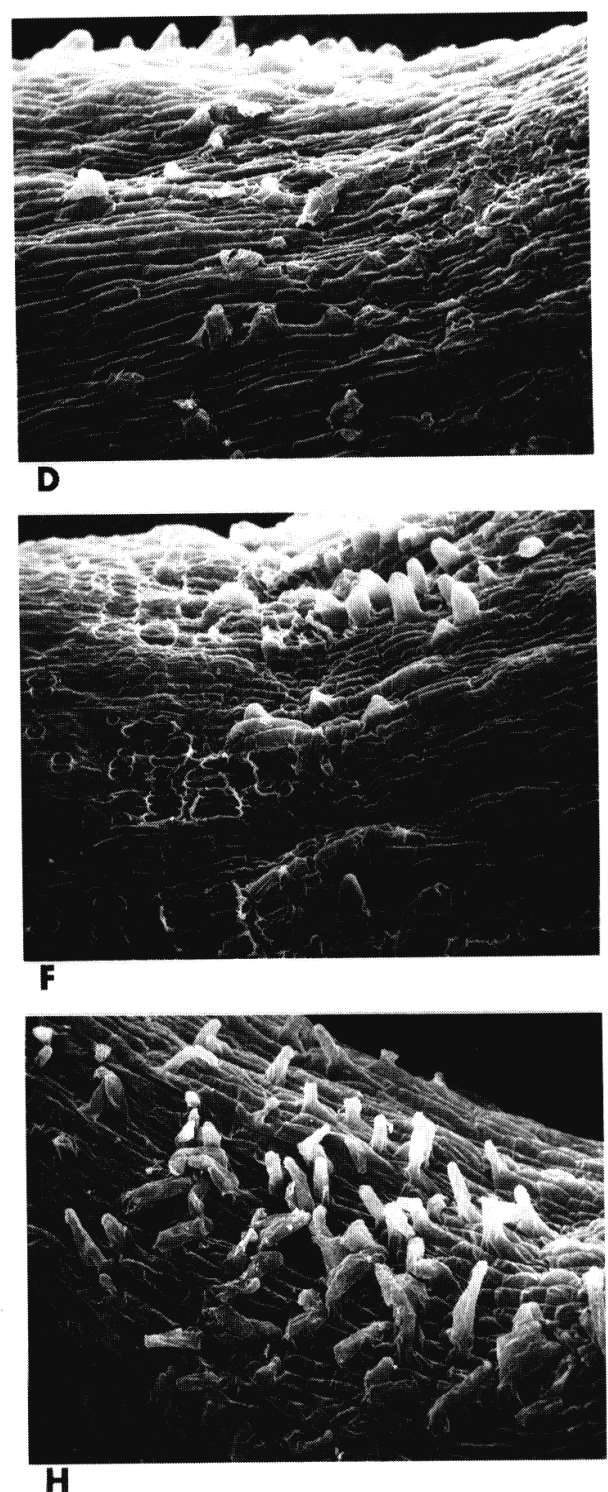

H

Fig 2. Comparative damage to 5-mm-lang radiches treated for 24 h with FA on CA, singly and in combination. Left-hand photographs show entire radicle ( $\times 37)$; right-hand photographs show wiew of affected area of the radiche $(\times 225)$. (A and B) Controbs; (C and D) $1 \%$ CA, (E and $\mathbf{F}) \quad 1 \% \quad \mathcal{F} ;$; (G and $\mathbf{H}) \quad 0.5 \% \quad \mathcal{F} / 0.5 \% \quad C d$.

treated pots (Table 2); however, the level of significance in treatment comparisons for the entire experiment indicated that the trends in both FO and DW main plots were generally similar (Table 2). FO and DW controls did not differ, but most of the cinnamic acid treatments showed a substantial reduction in emergence when in FO-treated pots (Table 1), again supporting evidence of the synergism that occurs when FO and the autotoxin or the extracts from it coexist in the soil. Single acid treatments ( $1 \%$ solutions) differed significantly (Table 2). CA was the least toxic, FA the most. Average effects of increasing single-acid dosages were predominantly linear in FO-treated pots, but data for DW fit linear and quadratic curves (Table 3). 


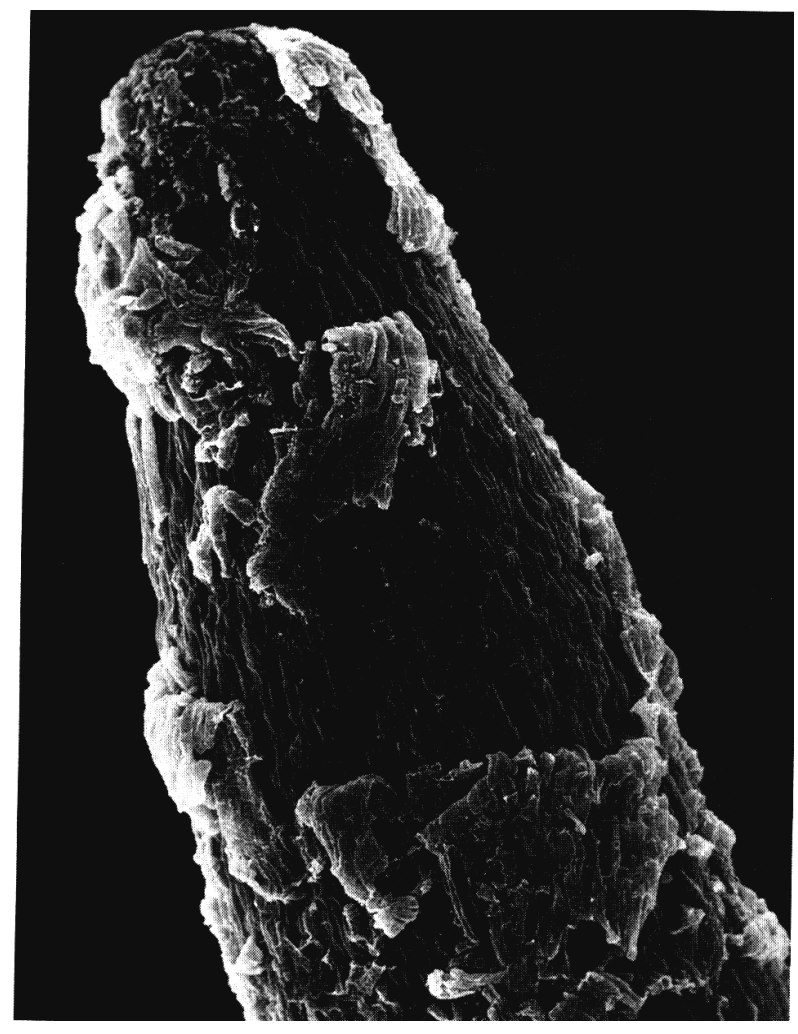

Fig. 3. Root tip $(\times 90)$ from combined FA + CA treatment, 2-h exposure, showing extensive surface erosion and apparent damage to subtending cells at the tip (compare with control in Fig. 2.)

The mixture of one cinnamic acid with a second intensified toxicity and the mixtures containing FA clearly were the most toxic $(\mathrm{P}<0.01)$, especially when in the presence of FO, but also in DW medium (Table 2). Further, there was a highly significant effect of dose (Table 3). As the proportion of FA in a mixture declined, emergence increased, generally in quadratic fashion although the number of dosages tested was too small to establish linearity or lack of it with certainty. The quadratic response in the presence of $\mathrm{FO}$, however, is consistent with previous results (Peirce and Colby, 1987). There was no significant difference between FA mixtures containing CA and those containing MDA (Table 2). In FO-treated pots, MDA was slightly less toxic in mixtures than CA, although differences were small (Table 3). The reverse was found for DW treatments. CA showed a quadratic dosage effect in DW medium, but no significant average trend in FO-treated pots.

Rinsing cinnamic acid residues from the seeds had no effect on number of seedlings emerging in either FO-treated or DW pots (data not reported). Apparently, the toxic effect occurred during soaking, and there was little effect of rinsing on the synergism between FO and cinnamic acids.

Experiment 2. Exposure of seeds after pregermination to FA, $\mathrm{CA}$, or FA/CA clearly demonstrated sensitivity of radicles to cinnamic acids (Fig. 1; Table 4). Of the two single-acid treatments, FA was the more toxic; however, when FA and CA were both present, the toxicity increased markedly, reducing emergence even after only a 10-min exposure.

Examination of root tips of treated radicles revealed a decline in number of mitotic cells, in comparison to water-treated controls (Table 5), and the decline was greatest, although differences were small, in the most toxic treatments as defined by emergence data. Also, as toxicity increased, radicles showed
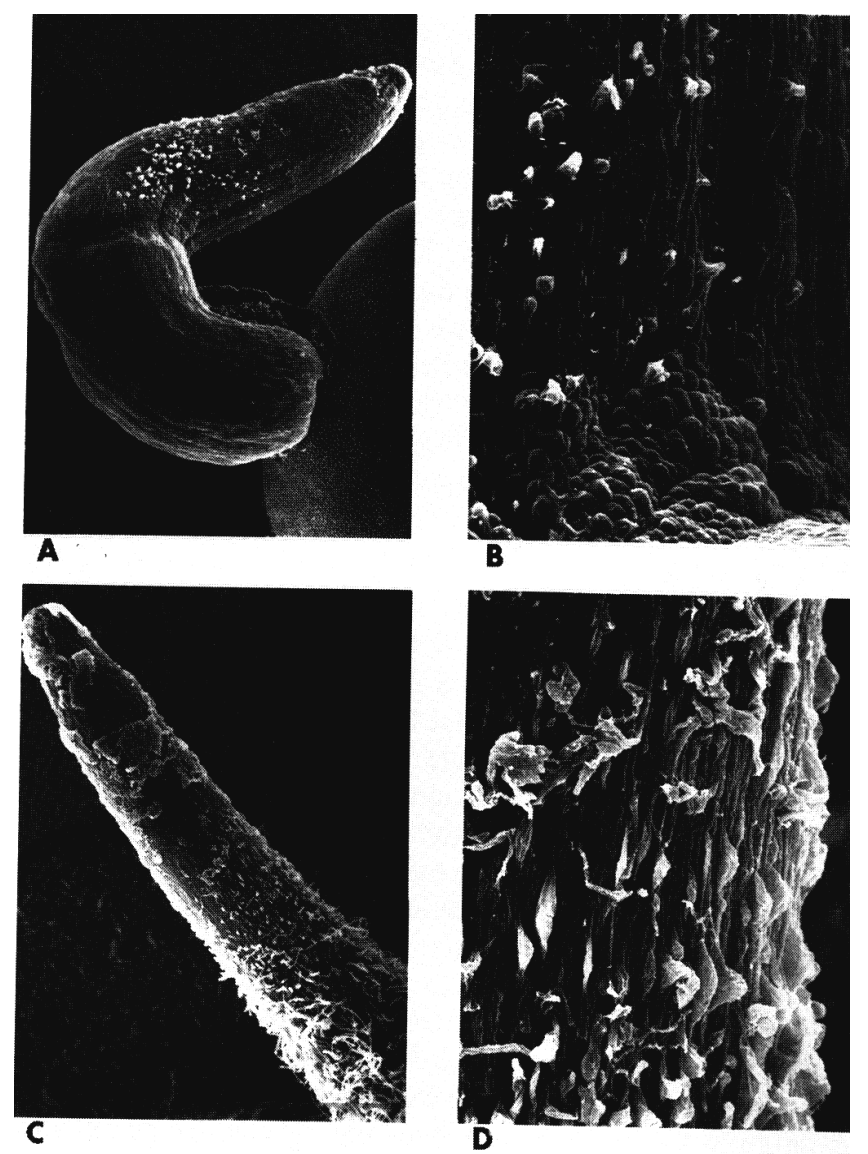

Fig. 4. Effect of length of exposure to combined FA + CA on amount of surface damage to radicles and on root hair development. Lefthand photographs show the radicle $(\times 37)$; right-hand photographs enlarge the area most affected (X 200). (A and B) 10-min exposure; (C and D) 2-h exposure (24-h exposure appears in Fig. 2).

increased browning. There was no apparent association of mitotic cell count with duration of treatment exposure, although browning was affected. One anomaly was observed in counts for the 2-h FA treatment that approached those of the controls. The reason for this anomaly is not clear, since the root tips showed the browning characteristic of the other toxic treatments.

SEM of treated and untreated radicles revealed extensive epidermal changes following the 24-h exposure to cinnamic acids. The changes were consistent for radicles $5 \mathrm{~mm}$ long but sporadic for those $2 \mathrm{~mm}$ long. As illustrated in Fig. 2, the changes were most severe in the FA/CA treatment, with progressively less effect in the $1 \% \mathrm{FA}$ and $1 \% \mathrm{CA}$ treatments, respectively, a trend that parallels emergence data from pot tests (Fig. 1). The treatment effects were characterized by an apparent erosion of some epidermal cell walls and a somewhat flaccid appearance of the epidermis relative to the control, particularly in an area near the "elbow" of the radicle. Rapid root hair development also was observed, the numbers. and lengths of which were consistent with treatment toxicity: the more toxic the treatment the more and longer the root hairs. Some of them appeared to have collapsed, but this appearance could have been an artifact resulting from sample preparation. Root tips also showed extensive epidermal tissue damage (Fig. 3), but again, damage by abrasion during sample preparation cold not be ruled out. However, damaged areas of the radicle as revealed by SEM were the same as those showing browning after treatment (Table 5). 
Figure 4 shows increasing effects of the FA/CA combined treatment after 10-min and 2-h exposures (compare with 24-h exposure, Fig $2 \mathrm{G}$ and $\mathrm{H}$ ). After $10 \mathrm{~min}$, root hair development was apparent, but the hairs appeared mostly turgid. The cell surface, however, showed some wrinkling, possibly a loss of turgidity, relative to the control. These appearance changes were pronounced in 2- and 24-h exposures. There were slight differences between the 2- and 24-h exposures, but both showed extensive root hair development and changes in epidermal cells. The photographic evidence of treatment damage also was consistent with emergence data: very few seedlings emerged from the 2- and 24-h FA/CA treatments (Fig. 1).

\section{Discussion}

Each of the cinnamic acids tested has been isolated from asparagus roots and found to be toxic to young asparagus. The data presented show that FA is more toxic than equal concentrations of CA or MDA and that the autotoxicity is severe when FA and either CA or MDA are both present. The increase in toxicity by combinations of cinnamic acids is unexplained, but the results are consistent with the report by Hartung et al. (1990) that none of the acids tested would alone account for phytotoxicity of the exudate from decaying roots.

Both root tips and epidermal cells of radicles were altered after exposure to cinnamic acids. It is doubtful if the decline in number of mitotic figures in root tips of treated radicles is directly related to synergism with Fusarium, although there could be a slowing of radicle growth, thus possibly increasing the opportunity for infection to take place. The epidermal changes seen in SEM examination of treated radicles, however, were extensive and possibly an important early factor in synergism.

The surface of epidermal cells showed some areas that appeared to be damaged or destroyed, and the surface of treated radicles as a whole appeared to be somewhat flaccid. The cinnamic acid treatment may have damaged epidermal cells, perhaps affecting permeability or perhaps providing lesions through which Fusarium could penetrate. We do not know if early appearance of root hairs is a factor in synergism. Root hairs are extensions of the epidermal cells, normally developing after cell elongation. Their appearance only in treated radicles is evidence that the treatments affected the growth sequence of epidermal cells. Further, since the tissue area in which these hairs appeared also developed browning, without the presence of Fusarium, and since SEM results and observed browning were consistent with treatment toxicity as determined by emergence data, hair damage could be a major factor enhancing Fusarium penetration of tissue in infested soils.

These tests have involved commercially obtained cinnamic acids. The autotoxin is, instead, a complex mixture in which several principal toxins have been identified (FA, CA, MDA). During the growing season, as damaged asparagus roots decay, the rhizosphere tends to retain these toxins (Yang, 1982). If the toxins damage surfaces of healthy root tips or the root hairs of developing roots in the same way as they damaged radicles in this study, Fusarium infection and subsequent decay of infected roots would be expected to increase, gradually increasing the level of toxin released to the rhizosphere. The evidence for this process is indirect but consistent with field and greenhouse observations.

In our experience, the level of toxicity in extracts from different samples of decaying roots has been variable, perhaps reflecting different relative concentrations of FA and CA. These concentrations might be affected by soil conditions, plant stress, or the stage of root decay. Asparagus decline is exacerbated by plant stress and stress was thought to simply weaken plant defenses to Fusarium infection Nigh, 1990. If stress also affected composition of the root decay exudate and thereby increased its toxicity, the synergism observed between autotoxin and fusarium disease also would be expected to intensify during these periods, and asparagus decline likely would accelerate.

Further insight with respect to synergism might be gained by using both light microscopy and SEM on material exposed to cinnamic acids and to Fusarium. Location of penetrating hyphae might give visual evidence that epidermal areas showing damage from cinnamic acid treatments are those in which fungal activity predominates.

\section{Literatures Cited}

Cohen S.I. and F.D. Heald. 1941. A wilt and root rot of asparagus caused by Fusarium oxysporum Schlect. Plant Dis. Rpt. 25:503609 .

Fantino, M.G. and F. Fantuz. 1990. The sanitary state of asparagus nurseries in Emelia-Romagna in 1988-1989. Acta Hort. 271:389394.

Grogan, R.G. and K.A. Kimball. 1959. The association of Fusarium wilt with asparagus decline and replant problems in California. Phytopathology 49:122-125.

Hartung, A.C., M.G. Nair, and A.R. Putnam. 1990. Isolation and characterization of phytotoxic compounds from asparagus (Asparagus officinalis L.) roots. J. Chem. Ecol. 16:(5):1707-1718.

Hartung, A.C., A.R. Putnam, and C.T. Stephens. 1989. Inhibitory activity of asparagus root tissue and extracts on asparagus seedlings. J. Amer. Soc. Hort. Sci. 114:144-148.

Hartung, A.C. and C.T. Stephens. 1983. Effects of allelopathic substances produced by asparagus on the incidence and severity of $\mathrm{Fu}$ sarium crown rot. J. Chem. Ecol. 9:1163-1174.

Hartung, A.C. and C.T. Stephens. 1984. Allelopathic properties of asparagus: interactions with Fusarium spp. and bioassay techniques. Phytopathology 74(7):800. (Abstr.)

Johnston, S.A., J.K. Springer, and G.D. Lewis. 1979. Fusarium moniliforme as a cause of stem and crown rot of asparagus and its association with asparagus decline. Phytopathology 69:778-780.

Miller, H.G., M. Ikawa, and L.C. Peirce. 1991. Caffeic acid identified as a toxic component from decaying asparagus roots. HortScience 26(12)1525-1527.

Nigh, C.L., Jr. 1990. Stress factors influencing Fusarium infection in asparagus. Acta Hort. 271:315-322.

Peirce, L.C. and L.W. Colby. 1987. Interaction of asparagus root filtrate with Fusarium oxysporum f. sp. asparagi. J. Amer. Soc. Hort. Sci. 112(1):35-40.

Rice, E.L. 1984. Allelopathy. Academic, Orlando, Fla. p. 274-275.

Sadowski, C. and M. Knaflewski. 1990. Susceptibility of selected asparagus cultivars to Fusarium spp. under field conditions. Acta Hort. 271:343-351.

Shafer, W.E. and S.A. Garrison. 1980a. Effects of decomposing asparagus root tissues on lettuce, tomato and asparagus seed emergence. HortScience 14:406. (Abstr.)

Shafer, W.E. and S.A. Garrison. 1980b. Effects of asparagus root extracts on lettuce and asparagus seed germination and growth. HortScience 14:406-407 (Abstr.)

Shafer, W.E. and S.A. Garrison. 1986. Allelopathic effects of soil incorporated asparagus roots on lettuce, tomato, and asparagus seedling emergence. HortScience 21(1):82-84.

Yang, H. 1982. Autotoxicity of Asparagus officinalis L. J. Amer. Soc. Hort. Sci. 107:860-862.

Young, C.C. 1984. Autotoxication in root exudates of Asparagus officinalis L. Plant \& Soil 82:247-253.

Young, C.C. 1986. Autotoxication of Asparagus officinalis, p. 101112. In: A.R. Putnam and C.S. Tang (eds.). The science of allelopathy. Wiley, New York. 